\title{
Is it Normal to have Alzheimer and Cancer at the Same Time?
}

\section{Soraya L Valles*}

Faculty of Medicine, Department of Physiology, University of Valencia, Spain

It can be a small consolation from any point of view, but different studies tells us that cancer patients develop less Alzheimer's disease, and Alzheimer's patients are less likely to get cancer. Obviously some people have both Alzheimer's disease and cancer, but are much less common than one would expect. Studies from Roe et al. at the School of Medicine at Washington University (St. Louis, USA), have indicated that observation about the relationship between illnesses, cancer and Alzheimer's disease [1]. Really, there are an inverse association and it give us one new way to discover what goes wrong in both cancer and Alzheimer's, and probably give us the possibility to treat both diseases with another point of view.

The effect was first observed in Parkinson's patients with cancer less often. Also studies with multiple sclerosis (MS) have been demonstrated to present fewer tumors, and furthermore in patients with Down syndrome, who can live to middle age or older. Years ago, Dr. Mary Behrens, with postdoctoral researcher in the Alzheimer's disease Research Center (ADRC) at Washington University, realized that there were few patients who had cancer. Dr. Roe and Dr. Behrens together with the collaborators developed a study with volunteers and founded that if the people with Alzheimer's disease develop cancer in the future, in that case it would develop more slowly. In the study, researchers followed 3,020 people over age 65 enrolled in the Cardiovascular Health Study, and the National Institute of Heart, Lung and Blood Institute. They followed the subject for an average of five years to see if they developed dementia and for an average of eight years to see if they were hospitalized for cancer. It was demonstrated that people with Alzheimer are 45 to $60 \%$ less likely to be hospitalized for cancer than those who did not have Alzheimer.

Could Alzheimer's be killing patients before being diagnosed with cancer? The epidemiologists have analytical techniques to adjust these deaths. Also, Dr. Roe and his collaborators have observed that patients with vascular dementia tend to die sooner than patients with Alzheimer have but have a higher risk of cancer than patients with Alzheimer.
On the other hand, we noticed that these studies were based on data taken from cancer hospitalization and from untreated and inoperable patients. The future of research will be to study a larger population of patients to see if the risk of developing Alzheimer's disease changes with respect to specific types of tumors, and whether certain types of cancer have greater or lesser effects on the risk of Alzheimer's.

Others epidemiologic studies have been reported relationship between cancer and Alzheimer's disease. In patients with Alzheimer's disease $(\mathrm{AD})$ a reduction in time to develop cancer and low rates of $\mathrm{AD}$ in cancer survivors has been indicated [2]. Scientists think that in the two disorders will be a deregulation in opposite ways of biological mechanisms of action, for example, susceptibility to cell death. Behrens and collaborators found significantly increased vulnerability of $\mathrm{AD}$ cells to $\mathrm{H}_{2} \mathrm{O}_{2}$-induced apoptotic death and higher resistance to death of cancer lymphocytes, due to reduced necrosis, as compared with healthy controls. These differences in the susceptibility to cell death observed from $\mathrm{AD}$ and cancer patients may be one of the mechanisms that helps in explaining the inverse correlation detected between these diseases in epidemiological studies.

Putting this information together makes us think that just like other works shows associations between cancer and Parkinson disease, the different findings in the last decade suggest the possibility that cancer is linked to neurodegeneration and perhaps we need to study more about the relation-ship and the differences between both cancer and neurodegeneration to understand how can we be attacked with these two illness in the future.

\section{References}

1. Roe CM, Fitzpatrick AL, Xiong C, Sieh W, Kuller L, et al. (2010) Cancer linked to Alzheimer disease but not vascular dementia. Neurology 74: 106-112.

2. Behrens MI, Silva M, Salech F, Ponce DP, Merino D, et al. (2012) Inverse Susceptibility to Oxidative Death of Lymphocytes Obtained From Alzheimer's Patients and Skin Cancer Survivors: Increased Apoptosis in Alzheimer's and Reduced Necrosis in Cancer. J Gerontol 10: 1036-1040.
*Corresponding author: Soraya L Valles, Faculty of Medicine, Department of Physiology, University of Valencia, Spain, Tel: 4-96-3864646; E-mail: Lilian.Valles@uv.es

Received February 05, 2013; Accepted February 05, 2013; Published February 07, 2013

Citation: Valles SL (2013) Is it Normal to have Alzheimer and Cancer at the Same Time? Anaplastology 2: 105. doi: 10.4172/2161-1173.1000105

Copyright: ( 2013 Valles SL. This is an open-access article distributed unde the terms of the Creative Commons Attribution License, which permits unrestricted use, distribution, and reproduction in any medium, provided the original author and source are credited. 